\title{
Staphylococcus aureus bacteremia with iliac artery endarteritis in a patient receiving ustekinumab
}

\author{
Insa Joost ${ }^{*^{*}}$ D, Johannes Steinfurt ${ }^{2}$, Philipp T. Meyer ${ }^{3}$, Winfried V. Kern ${ }^{1}$ and Siegbert Rieg ${ }^{1}$
}

\begin{abstract}
Background: Ustekinumab (Stelara ${ }^{\circledR}$ ), a human monoclonal antibody targeting the p40-subunit of interleukin (IL)-12 and IL-23, is indicated for moderate to severe plaque psoriasis and psoriatic arthritis. In large multicenter, prospective trials assessing efficacy and safety of ustekinumab increased rates of severe infections have not been observed so far.

Case presentation: Here, we report the case of a 64-year old woman presenting with chills, pain and swelling of her right foot with dark maculae at the sole, and elevated inflammatory markers. She had received a third dose of ustekinumab due to psoriatic arthritis three days before admission. Blood cultures revealed growth of Staphylococcus aureus and imaging showed a thickening of the aortic wall ventral the bifurcation above the right internal iliac artery, resembling an acute bacterial endarteritis. Without the evidence of aneurysms and in absence of foreign bodies, the decision for conservative management was made. The patient received four weeks of antibiotic therapy with intravenous flucloxacillin, followed by an oral regime with levofloxacin and rifampicin for an additional four weeks. Inflammatory markers resolved promptly and the patient was discharged in good health.

Conclusion: To our knowledge, this is the first report of a severe $S$. aureus infection in a patient receiving ustekinumab. Albeit ustekinumab is generally regarded as a safe drug, severe bacterial infections should always be included in the differential diagnosis of elevated inflammatory markers in patients receiving biologicals as these might present with nonspecific symptoms and fever might be absent. Any effort to detect deep-seated or metastatic infections should be made to prevent complications and to secure appropriate treatment. Although other risk factors for an invasive staphylococcal infection like psoriasis, recent corticosteroid injection, or prior hospitalisations were present, and therefore a directive causative link between the $\mathrm{S}$. aureus bacteraemia and ustekinumab can not be drawn, we considered the reporting of this case worthwhile to alert clinicians as we believe that ongoing pharmacovigilance to detect increased risks for rare but severe infections beyond phase II and phase III trials in patients treated with biologicals is essential.
\end{abstract}

Keywords: Immunosuppression, Biologicals, IL-12, IL-23, Intravascular infection

\section{Background}

Staphylococcus aureus is one of the most common causative organisms of community-acquired or healthcareassociated bloodstream infections (BSI) [1, 2]. Inhouse mortality of $S$. aureus bacteremia (SAB) is considerably high (20-30 \%) [3]. According to a population based study, patients with severe psoriasis have a higher risk for serious

\footnotetext{
* Correspondence: insa.joost@uniklinik-freiburg.de

'Division of Infectious Diseases, Department of Medicine II, University Medical Center Freiburg, Hugstetter Str. 55, Freiburg 79106, Germany

Full list of author information is available at the end of the article
}

infections with significantly more hospitalizations for skin infections [4] compared to the reference population. Moreover, patients with psoriasis are more frequently colonized with $S$. aureus than the normal population, yet are not regarded as particularly susceptible to $S$. aureus infections, which may be due to a pronounced induction of innate defense antimicrobial peptides in psoriatic skin lesions $[5,6]$. However, a small study reported the occurrence of $S$. aureus bacteremia in patients with extensive disease i.e. erythrodermic psoriasis [7]. 
A large prospective study in France in patients receiving TNF- $\alpha$ antagonists mainly due to rheumatoid or psoriatic arthritis, found $S$. aureus as the dominant causative pathogen of BSI, including all recorded deaths and intensive care admissions. The majority of patients with $S$. aureus BSI experienced subsequent osteoarticular manifestations (63 vs. $4 \%$ in BSI patients due to other pathogens) [8].

Ustekinumab is a human monoclonal antibody that binds to the p40-subunits of interleukin (IL)-12 and IL-23 thereby preventing binding of these cytokines to their respective receptors and inhibiting $\mathrm{T}$ cell activation. Ustekinumab was approved by the FDA and EMA in 2009 for the treatment of adult patients with moderate to severe plaque psoriasis as well as patients with active psoriatic arthritis alone or in combination with methotrexate.

Like other immunosuppressive agents, ustekinumab may potentially increase the risk for acquiring infections or predispose to unusual or particularly severe manifestations of infections or to activate latent infections. Product labels of ustekinumab include warnings of serious infections and advise not to start the therapy during clinically important infections, to stop its application in case a serious infection develops and to use it with caution in patients with chronic or recurrent infections. A pretreatment tuberculosis screen is recommended. However, in large multicenter trials infection rates were not elevated compared to other biologicals or non-biological immunosuppressive agents [9-14].

In the following article we report the case of a 64year old woman receiving ustekinumab due to psoriatic arthritis who developed $S$. aureus bacteremia with iliac artery endarteritis.

\section{Case presentation}

A 64-year old Caucasian woman presented in March 2014 to the emergency department with severe pain and swelling of her right foot. She also noticed small, dark lesions on the sole of her right foot. She denied fever but reported chills for several days (timeline see Fig. 1). No other symptoms were present. She had a history of plaque psoriasis and psoriatic arthritis since 2010. In the past she had received etanercept (stopped in 2010), adalimumab (stopped 2011), cyclosporine (stopped February 2013) and golimumab (stopped Oktober 2013) without significant clinical improvement. She was started on ustekinumab (45 mg subcutanously) in March 2014, received the second dose in April and the third dose three days before hospitalisation. One day before presentation, she had received a steroid injection in the right sacroiliac joint because of aggravation of pain in the lumbosacral region. Her medical history was remarkable for an alcohol induced liver cirrhosis (Child-Pugh stage
B), arterial hypertension and breast cancer (stage pT1c, pN1a, M0; resection and radiation in 2006, since then in remission). On admission, the patient was afebrile $\left(36.8{ }^{\circ} \mathrm{C}\right)$ and the vital signs were within normal ranges (blood pressure $140 / 80 \mathrm{mmHg}$, pulse $87 / \mathrm{min}$ ). The clinical examination revealed swelling of her right ankle and multiple non-elevated dark maculae on the sole of her right foot (Fig. 2a and b) resembling Janeway lesions. All joints were tender on palpation with particular pain in the right sacroiliac joint. Multiple psoriatic lesions were present. Laboratory analysis revealed a leukocytosis of $23 \times 10$ [9] cells/L, a reduced platelet count of $66 \times 10$ [9] cells/L, a C-reactive protein level of $154 \mathrm{mg} / \mathrm{L}$ [ $<5 \mathrm{mg} / \mathrm{L}]$, a procalcitonin of $4.67 \mathrm{ng} / \mathrm{mL}$ [<0.5 ng/mL], a blood urea nitrogen of $93 \mathrm{mg} / \mathrm{dl}$, a serum creatinine of $1.16 \mathrm{mg} / \mathrm{dl}$ and an INR 1.35. A CT scan on the day of admission showed no signs of arthritis, joint effusion or empyema in the right ankle joint. However, edema and thickening of the aortic/right common iliac artery wall at the aortic bifurcation, consistent with an inflammatory vascular lesion, was noted (Fig. 3a and b). Without an unambiguous focus (and prior to the CT scan) the patient had been started on an empiric antibiotic therapy with intravenous piperacillin/tazobactam ( $4.5 \mathrm{~g}$ every $8 \mathrm{~h}$ ) and oral clarithromycin $(500 \mathrm{mg} / \mathrm{d})$. The next day, the patient's condition improved. Blood cultures yielded growth of $S$. aureus (susceptible to methicillin, fluoroquinolones, clindamycin and rifampicin). Antibiotic treatment was modified to intravenous flucloxacillin (4 g every $8 \mathrm{~h}$ ). Transesophageal echocardiography revealed no evidence for infective endocarditis. Rheumatoid factor was negative and the urine analysis did not show signs of proteinuria or hematuria. A follow-up CT scan 12 days later confirmed arterial wall thickening at the aortic bifurcation with a soft tissue cuff above the right common iliac artery with no evidence for progression. An additional FDG-PET/CT scan demonstrated increased metabolism in this vessel segment (Fig. 4a-c). Apart from moderate inflammatory activity in the right sacroiliac joint no other hypermetabolic foci were detected.

The patient was treated for four weeks with intravenous flucloxacillin and was discharged with an oral regime consisting of levofloxacin $(500 \mathrm{mg} / \mathrm{d})$ and rifampicin (450 mg twice daily) for another four weeks. One month after completion of the antibiotic therapy the patient was well with no signs of active infection or recurrence. A report was filed with the Federal Institute for Drugs and Medical Devices (BfArm).

\section{Conclusions}

To our knowledge, this is the first published report of a severe $S$. aureus infection in a patient receiving ustekinumab. Ustekinumab is a rather new biological 


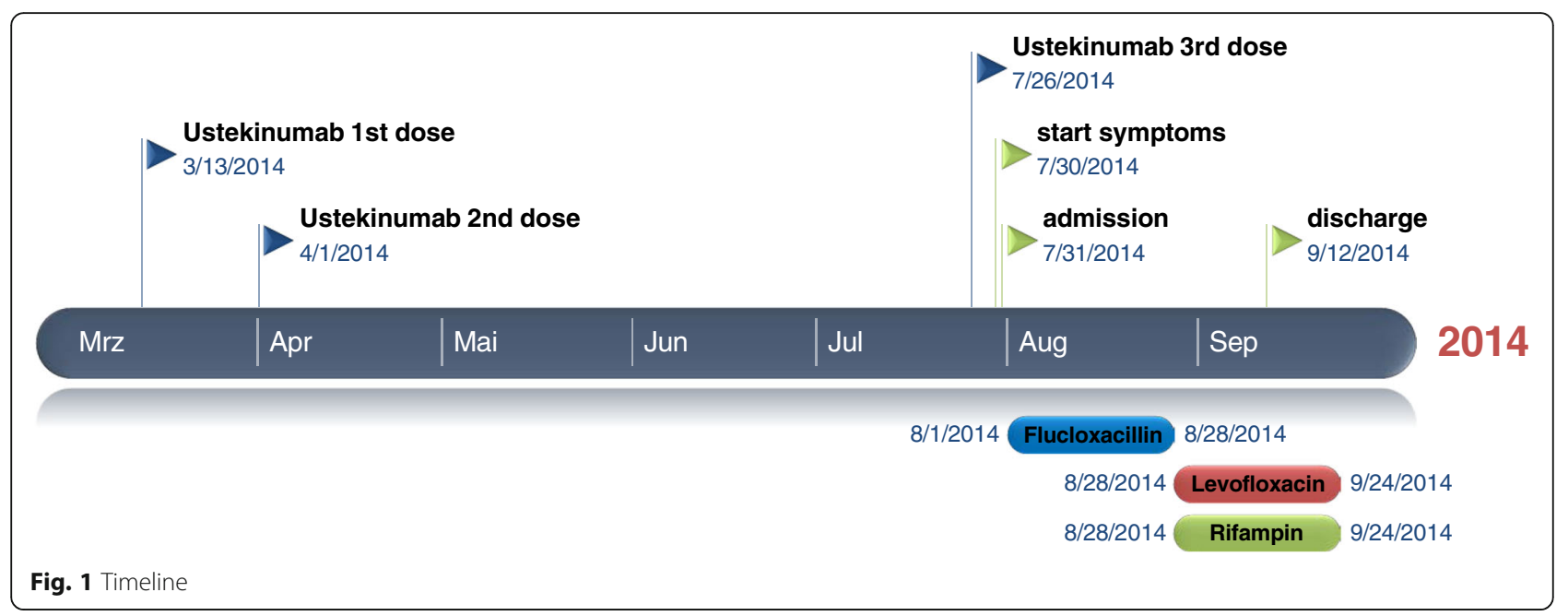

immunosuppressive agent that is used in moderate to severe plaque psoriasis and otherwise unresponsive active psoriatic arthritis. Its efficacy and safety has been studied in a multicenter, prospective, disease-based registry (Psoriasis Longitudinal Assessment and Registry [PSOLAR]) [12] as well as in multiple large multicenter trials [10, 13-16]. Ustekinumab is considered to be well tolerated, most adverse events are mild and do not require dosage adjustment or cessation of therapy [17]. Clinical trial data available so

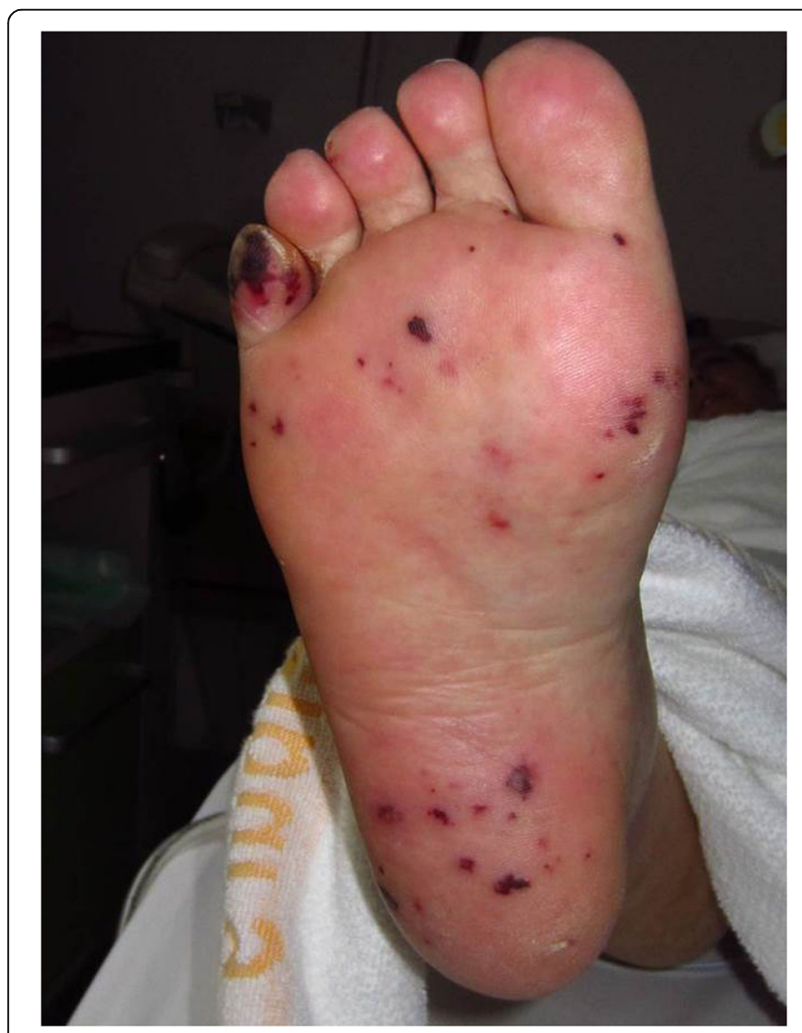

Fig. 2 Multiple dark maculae on the sole of the right foot resembling septic emboli/Janeway lesions far indicate no increased incidence of severe infections compared to placebo or other biologicals and no specific patterns of infection could be observed [9, 11-13, 17, 18]. The PSOLAR registry included 4134 patients receiving ustekinumab. The cumulative incidence for serious infections was $0.95 / 100$ patient years compared to 1.26 for nonbiologicals and 2,78 for infliximab.

IL-12 plays an important role for the optimal production of IFN- $\gamma$ by T cells and NK cells [19]. Patients with an inherited defect in the IFN- $\gamma /$ IL-12 pathway show a decreased IFN- $\gamma$ production due to a disturbed interaction between phagocytes and $\mathrm{T}$ lymphocytes and an increased susceptibility to infections with microorganisms of the genera Mycobacterium and Salmonella [20-22]. Severe $S$. aureus infections have not been documented so far in such patients or patients receiving ustekinumab. Of note, IL-23 stimulates Th-17 cell development. Recent evidence suggests that Th-17 cells contribute to cutaneous defense against $S$. aureus [23]. As ustekinumab indirectly inhibits Th-17 pathways this may be regarded as a theoretical and of course purely speculative explanatory model for a propensity/higher susceptibility for $S$. aureus infections. In general, patients receiving biologicals and other immunosuppressive agents for the treatment of rheumatologic disorders may be at increased risk for severe infections due to different reasons. In addition to the immunsupressive treatment, these patients are frequently exposed to injections for application of drugs but also for diagnostic or therapeutic intraarticular punctures. Moreover, psoriatic skin lesions have been shown to be more frequently colonized by $S$. aureus than healthy skin [24]. In our case of a healthcareassociated $S$. aureus bacteremia the portal of entry remains unclear. Potential entry sites include psoriatic skin lesions or intravascular catheters (which were present during previous hospitalisations). The inflammatory erosive changes of joints seen in psoriatic (or rheumatoid) 


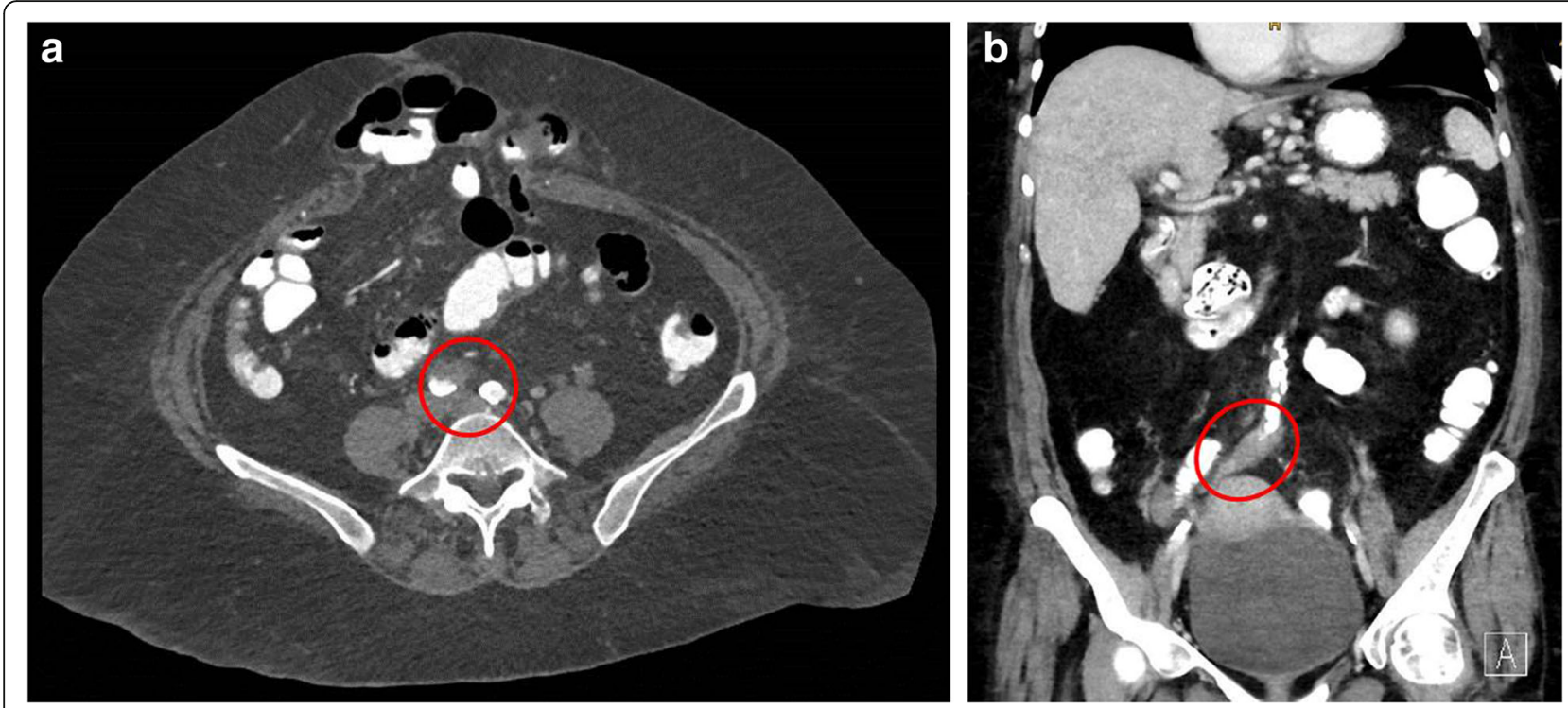

Fig. $\mathbf{3}$ a and $\mathbf{b}$ CT scan showing an aortic wall thickening at the aortic bifurcation with a soft tissue cuff above the right common iliac artery consistent with endarteritis

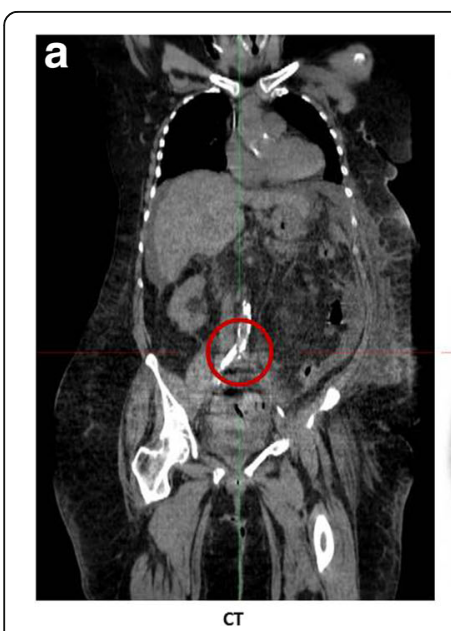

CT

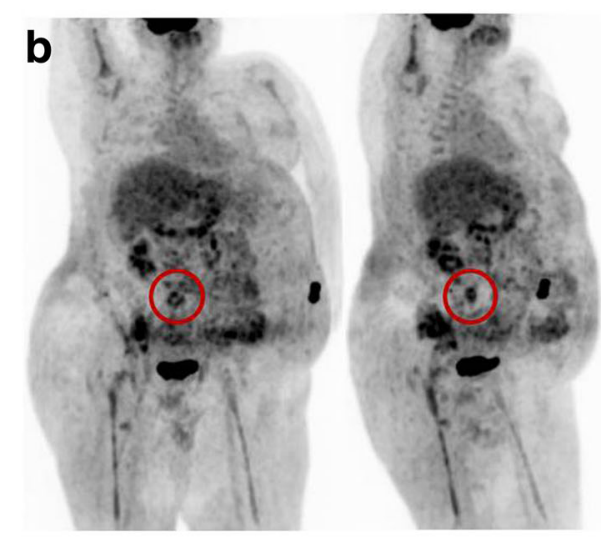

PET maximum intensity projection

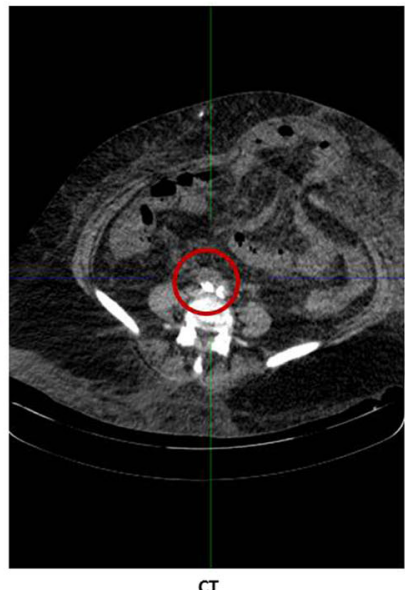

CT

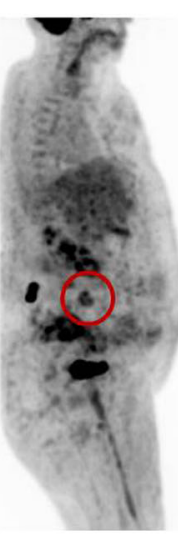

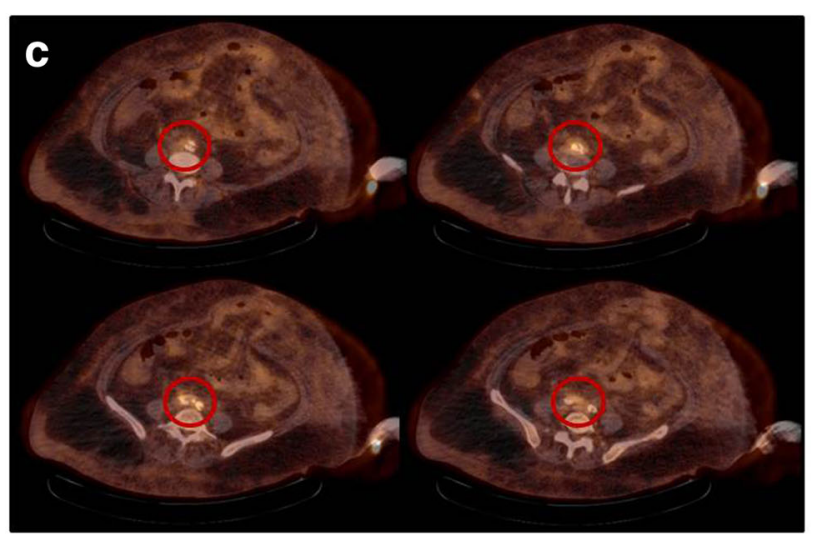

PET/CT fusion image

Fig. 4 a-c FDG-PET/CT scan showing increased metabolism at the soft tissue cuff above the right common iliac artery 
arthritis may represent an independent risk factor for osteoarticular infections, as increased adherence to inflammatory altered joint surfaces likely accentuates seeding of pathogens such as S. aureus [25-27].

However, we found no clear evidence for $S$. aureus infection of the sacroiliac joint secondary to injection therapy. Moreover, extension from a contiguous focus was considered highly unlikely as surrounding tissue was without pathological findings in several radiological examinations.

Endarteriitis as seen in our case represents a rare diagnosis in the absence of endovascular prosthesis or preexisting aneurysm. However, hematogenous seeding in the endothelium of an otherwise intact arterial intima during bacteremia may occur and $S$. aureus is the predominant pathogen in this context. Our patient had a number of risk factors that might have contributed to the observed severe infection like psoriatic lesions, injection therapy and pior hospitalizations. Besides ustekinumab, our patient had received a number of different immunosuppressive drugs in the past, however, the latest 5 month prior to the reported infection. Of course, in these complex clinial setting, it is not possible to unambiguously assign ustekinumab as the underlying cause for this infection and this is not the intention of our report. However, we believe that in terms of pharmacovigilance, reporting of such cases is important.

\begin{abstract}
Abbreviations
BfArm: Bundesanstalt für Arzneimittel und Medizinprodukte (Federal Institute for Drugs and Medical Devices); BSI: Blood stream infection; EMA: European Medicines Agency; FDA: Federal Drug Agency; PSOLAR: Psoriasis Longitudinal Assessment and Registry; SAB: Staphylococcus aureus bacteremia; TNF-a: Tumor necrosis factor alpha
\end{abstract}

\section{Acknowledgements}

We thank K. Stete and F. Küpper for providing clinical data.

\section{Funding}

No funding has been received by any of the authors or acknowledged persons for the conduct of this study and/or preparation of this manuscript.

\section{Availability of data and materials}

The datasets supporting the conclusions of this article are included within the article.

\section{Authors' contributions \\ IJ and SR drafted the manuscript and performed a literature review. JS, SR and WK were involved in clinical care or served as attending physicians. PM performed and analysed radiological investigations. All authors read and approved the final manuscript}

\section{Competing interests}

The authors declare that they have no competing interests.

\section{Consent for publication}

Written informed consent was obtained from the patient for publication of this case report.

Ethics approval and consent to participate Not applicable.

\section{Author details}

'Division of Infectious Diseases, Department of Medicine II, University Medical Center Freiburg, Hugstetter Str. 55, Freiburg 79106, Germany. ${ }^{2}$ Department of Cardiology and Angiology I, Heart Center, University of Freiburg, Hugstetter Strasse 55, Freiburg 79106, Germany. ${ }^{3}$ Department of Nuclear Medicine, University Medical Center Freiburg, Hugstetter Str. 55, Freiburg 79106, Germany.

Received: 4 May 2016 Accepted: 11 October 2016

Published online: 20 October 2016

\section{References}

1. Fluit AC, Jones ME, Schmitz FJ, Acar J, Gupta R, Verhoef J. Antimicrobial susceptibility and frequency of occurrence of clinical blood isolates in Europe from the SENTRY antimicrobial surveillance program, 1997 and 1998. Clin Infect Dis. 2000;30(3):454-60

2. Laupland KB, Church DL. Population-based epidemiology and microbiology of community-onset bloodstream infections. Clin Microbiol Rev. 2014;27(4):647-64.

3. Kaasch AJ, Barlow G, Edgeworth JD, Fowler Jr VG, Hellmich M, Hopkins S, et al. Staphylococcus aureus bloodstream infection: a pooled analysis of five prospective, observational studies. J Infect. 2014;68(3):242-51.

4. Wakkee M, de Vries $E$, van den Haak P, Nijsten T. Increased risk of infectious disease requiring hospitalization among patients with psoriasis: a population-based cohort. J Am Acad Dermatol. 2011;65(6):1135-44.

5. Marples RR, Heaton CL, Kligman AM. Staphylococcus aureus in psoriasis. Arch Dermatol. 1973;107(4):568-70.

6. Ong PY, Ohtake T, Brandt C, Strickland I, Boguniewicz M, Ganz T, et al. Endogenous antimicrobial peptides and skin infections in atopic dermatitis. N Engl J Med. 2002;347(15):1151-60.

7. Green MS, Prystowsky JH, Cohen SR, Cohen Jl, Lebwohl MG. Infectious complications of erythrodermic psoriasis. J Am Acad Dermatol. 1996;34(5 Pt 2):911-4.

8. Loulergue P, Tubach F, Salmon D, Dellamonica P, Taillan B, Thorel JB, et al. Bacteremia in patients receiving TNF-alpha antagonists-a prospective multicenter study. J Infect. 2013;67(6):524-8.

9. Correr CJ, Rotta I, Teles TS, Godoy RR, Riveros BS, Garcia MM, et al. Efficacy and safety of biologics in the treatment of moderate to severe psoriasis: a comprehensive meta-analysis of randomized controlled trials. Cad Saude Publica. 2013;29 Suppl 1:S17-31.

10. Gordon KB, Papp KA, Langley RG, Ho V, Kimball AB, Guzzo C, et al. Long-term safety experience of ustekinumab in patients with moderate to severe psoriasis (Part II of II): results from analyses of infections and malignancy from pooled phase II and III clinical trials. J Am Acad Dermatol. 2012;66(5):742-51.

11. Liu Y, Gong JP, Li WF. Therapeutic effect and safety of ustekinumab for plaque psoriasis: a meta-analysis. Chin Med Sci J. 2014;29(3):131-8.

12. Papp K, Gottlieb AB, Naldi L, Pariser D, Ho V, Goyal K et al. Experience with ustekinumab in patients with psoriasis enrolled in a large, multicenter, prospective, disease-based registry (Psoriasis Longitudinal Assessment and Registry [PSOLAR]). J Am Acad Dermatol 2015.

13. Papp KA, Griffiths CE, Gordon K, Lebwohl M, Szapary PO, Wasfi Y, et al. Longterm safety of ustekinumab in patients with moderate-to-severe psoriasis: final results from 5 years of follow-up. Br J Dermatol. 2013;168(4):844-54.

14. Toussirot $E$, Michel F, Bereau M, Binda D. Ustekinumab in chronic immunemediated diseases: a review of long term safety and patient improvement. Patient Prefer Adherence. 2013;7:369-77.

15. Kimball AB, Papp KA, Wasfi Y, Chan D, Bissonnette R, Sofen H, et al. Longterm efficacy of ustekinumab in patients with moderate-to-severe psoriasis treated for up to 5 years in the PHOENIX 1 study. J Eur Acad Dermatol Venereol. 2013;27(12):1535-45.

16. Zhu $X$, Zheng $M$, Song $M$, Shen $Y K$, Chan D, Szapary PO, et al. Efficacy and safety of ustekinumab in Chinese patients with moderate to severe plaquetype psoriasis: results from a phase 3 clinical trial (LOTUS). J Drugs Dermatol. 2013;12(2):166-74

17. Hayashi M, Umezawa Y, Fukuchi O, Ito T, Saeki H, Nakagawa H. Efficacy and safety of ustekinumab treatment in elderly patients with psoriasis. J Dermatol. 2014:41(11):974-80.

18. Kimball AB, Gordon KB, Fakharzadeh S, Yeilding N, Szapary PO, Schenkel B, et al. Long-term efficacy of ustekinumab in patients with moderate-tosevere psoriasis: results from the PHOENIX 1 trial through up to 3 years. Br J Dermatol. 2012;166(4):861-72. 
19. Trinchieri G. Cytokines acting on or secreted by macrophages during intracellular infection (IL-10, IL-12, IFN-gamma). Curr Opin Immunol. 1997;9(1):17-23.

20. Al-Herz W, Bousfiha A, Casanova JL, Chatila T, Conley ME, CunninghamRundles $C$, et al. Primary immunodeficiency diseases: an update on the classification from the international union of immunological societies expert committee for primary immunodeficiency. Front Immunol. 2014;5:162.

21. Carvalho BT, lazzetti AV, Ferrarini MA, Campos SO, lazzetti MA, Carlesse

FA. [Salmonella septicemia associated with interleukin 12 receptor beta] (IL-12Rbeta1) deficiency]. J Pediatr (Rio J). 2003;79(3):273-6.

22. Diniz LM, Guimaraes T, Oliveira M, Pinto JA, Miranda SS. Lymphadenitis caused by infection with an isoniazid- and rifampin-resistant strain of Mycobacterium bovis BCG in an infant with IFN-gamma/IL-12 pathway defect. J Bras Pneumol. 2014;40(2):188-92.

23. Cho JS, Pietras EM, Garcia NC, Ramos RI, Farzam DM, Monroe HR, et al. IL-17 is essential for host defense against cutaneous Staphylococcus aureus infection in mice. J Clin Invest. 2010;120(5):1762-73.

24. Balci DD, Duran N, Ozer B, Gunesacar R, Onlen Y, Yenin JZ. High prevalence of Staphylococcus aureus cultivation and superantigen production in patients with psoriasis. Eur J Dermatol. 2009;19(3):238-42.

25. Dubost JJ, Soubrier M, Sauvezie B. Pyogenic arthritis in adults. Joint Bone Spine. 2000;67(1):11-21.

26. Favero M, Schiavon F, Riato L, Carraro V, Punzi L. Septic arthritis: a 12 years retrospective study in a rheumatological university clinic. Reumatismo. 2008; 60(4):260-7.

27. Gomez RN, Ibanez RJ, Gonzalez M, Pintado A, Penelas CY. Peripheral septic arthritis in adults. Epidemiologic study in a Galician health area. An Med Interna. 2001:18(11):573-7.

\section{Submit your next manuscript to BioMed Central and we will help you at every step:}

- We accept pre-submission inquiries

- Our selector tool helps you to find the most relevant journal

- We provide round the clock customer support

- Convenient online submission

- Thorough peer review

- Inclusion in PubMed and all major indexing services

- Maximum visibility for your research

Submit your manuscript at www.biomedcentral.com/submit 